\title{
Underreporting of energy intake from a self-administered food-frequency questionnaire completed by adults in Montreal
}

\author{
Daniel Bedard ', Bryna Shatenstein ${ }^{1,2, *}$ and Sylvie Nadon ${ }^{2}$ \\ ${ }^{1}$ Centre de Recherche, Institut Universitaire de Gériatrie de Montréal, 4565 Queen Mary, Montréal, Québec, \\ Canada, H3W 1W5: 2Département de Nutrition, Université de Montréal, Montréal, Québec, Canada
}

Submitted 30 July 2003: Accepted 25 November 2003

\begin{abstract}
Background: Energy intake determined from self-reported dietary assessment methods may be underreported. Therefore, it is important that such methods be validated against another with known validity for energy intake or energy expenditure.

Methods: We investigated potential underestimation of energy intake obtained from our semi-quantitative food-frequency questionnaire (FFQ) administered between 2000 and 2001 in the metropolitan area of Montreal, Canada. The study population included 246 adults aged 18 to 82 years. The ratio of energy intake to estimated basal metabolic rate (EI/BMR) was used to assess underreporting and physical activity was determined from self-administered questions. Comparison of the EI/BMR ratio with the Goldberg statistical cut-off allowed us to detect individuals who were low energy reporters (LERs). LERs and non-LERs were compared to determine if they differed on sociodemographic, anthropometric and lifestyle variables.

Results: The EI/BMR ratio was 1.26 for men and 1.32 for women. LERs represented $43 \%$ of the sample of individuals. Male LERs accounted for 54\% compared with $35 \%$ among females. Underreporting of energy intake was highest in men and individuals who were older, heavier, with higher body mass index and lower education level. A higher proportion of male LERs perceived their financial situation as adequate while a greater proportion of female LERs considered themselves poor.

Conclusion: Our data suggest that underreporting of energy intake from the FFQ was considerable and may bias dietary interpretation. As this was uneven across the sample, it is crucial to recognise the characteristics of LERs in order to increase the validity of reported energy intake.
\end{abstract}

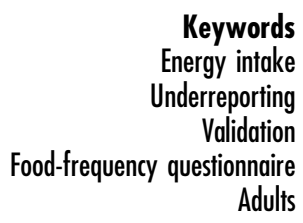

Adults
A recurrent issue in dietary self-reports is the extent to which participants underreport their energy intake. This is a particular problem when assessing habitual diet ${ }^{1}$. All methods designed to estimate population food and nutrient intakes are subject to bias ${ }^{2}$. It was only with the doubly labelled water method in the 1980s that it became possible to determine the validity of energy intake from dietary assessment methods using an external independent marker in free-living populations ${ }^{3}$. However, the cost and complexity of the doubly labelled water method makes it impracticable in large epidemiological studies. As a result, a method was developed by Goldberg et al. ${ }^{4}$ based on the ratio of energy intake to basal metabolic rate (EI/BMR) which can be used to determine whether it is likely that weight-stable individuals have underreported their energy intake. A review by Black et al. determined that underreporting was widespread in the vast majority of nutritional studies regardless of the dietary assessment method $^{5}$.
Many factors and behaviours may explain underreporting of energy intake in different populations, including physiological (weight status, body fat) ${ }^{6,7}$, sociodemographic (age, gender) ${ }^{8}$ and psychological (social desirability, body dissatisfaction $)^{9,10}$ reasons and lifestyle attributes or characteristics (smoking, physical activity) ${ }^{11}$. Some studies have also found differential reporting of macronutrient and nutrient intakes in low energy reporters (LERs) ${ }^{12,13}$. Goris et al. showed that underreporting could result from either under-recording or under-eating by the individual during the assessment period, or a combination of both ${ }^{14}$. Underreporting of energy intakes could also be explained by lack of precision in the assessment instrument (i.e. not enough food items in the foodfrequency questionnaire (FFQ)), or by the inability, difficulty or respondents' lack of motivation accurately to report their intakes ${ }^{7}$.

The present paper reports an investigation of underreporting of energy intake from an FFQ developed 
to evaluate usual dietary and nutrient intakes among adults living in Montreal, Canada ${ }^{15}$. The aims of the study were to evaluate the prevalence of underreporting of energy intake from the FFQ and to compare physiological, sociodemographic and lifestyle characteristics of LERs and non-LERs.

\section{Methods}

\section{Study population}

The study participants were adults living in the metropolitan area of Montreal, Quebec, Canada. They were recruited between November 2000 and August 2001 using random digit dialling ${ }^{16}$ and eligible adults were invited to participate in the study. Recruitment of potential subjects was achieved with $57.3 \%$ of valid telephone numbers ( 522 of 911). The 400 respondents who agreed to participate received a personalised invitation, consent forms and the FFQ by mail. The final study sample included 248 adults aged 18 to 82 years who provided an adequately completed FFQ. Two subjects were subsequently excluded due to extreme reported energy intakes (more than three standard deviations (SD) above the mean), and the final sample consisted of 106 men and 140 women in four age categories (18-34, 35-49, 50-64 and $65+$ years).

The study was approved by the Research Ethics Committee of the Institut Universitaire de Gériatrie de Montréal. Each subject provided written informed consent.

\section{Dietary assessment}

A 73-item, self-administered, semi-quantitative FFQ was adapted to the dietary reality of Quebecers from the Health Habits and History Questionnaire developed by Block et al. at the National Cancer Institute ${ }^{17}$. The FFQ was designed to be relatively brief and assess habitual food and nutrient intakes, and be representative of sociodemographic groups. Subjects were required to report their consumption frequency and portion size (smaller, equal to, or larger than the reference) of foods and beverages consumed during the previous 12 months in each of the 73 food categories. The FFQ also contained photos of portion sizes of different foods and beverages. Complete details of the FFQ development and validation and of the dietary assessment procedure are provided elsewhere ${ }^{18,19}$.

\section{Assessment of lifestyle variables}

Data on other dietary habits, supplement use, physical activity, weight and height, smoking and sociodemographic information were gathered at the end of the FFQ. Participants were categorised by age group (18-34 years; 35-49 years; 50-64 years; $65+$ years) and three body mass index (BMI) groups $\left(<25.0 \mathrm{~kg} \mathrm{~m}^{-2} ; 25.0-\right.$ $30.0 \mathrm{~kg} \mathrm{~m}^{-2} ;>30.0 \mathrm{~kg} \mathrm{~m}^{-2}$ ). Perceived financial situation (adequate or poor), level of education (less than secondary education, or college and higher) and physical activity (light, or moderate and higher) were each grouped to form two categories in order to compare LERs and nonLERs on these characteristics.

\section{Evaluation of energy intake underreporting}

The method developed by Goldberg et al. based on EI/BMR ratio was employed to determine underreporting of energy intake ${ }^{4}$ as reported in the FFQ. Schofield's equations based on age and reported body weight and height, provided in the FFQ, were used to estimate $\mathrm{BMR}^{20}$. Data on self-reported physical activity (see Appendix) permitted the classification of subjects into categories of light, moderate or heavy physical activity level (PAL), defined as the ratio of energy expenditure divided by estimated basal metabolic rate (EE/BMR), using the energy requirements recommended by the Food and Agriculture Organization (FAO)/World Health Organization (WHO)/ United Nations University (UNU) ${ }^{21}$. The PAL values were 1.55, 1.78 and 2.10 for men, and 1.56, 1.64 and 1.82 for women. We inserted each participant's EE/BMR ratio into Goldberg's cut-off equation to calculate a limit for each participant, where the multiplication of the limit by the BMR gave a level of energy intake considered to be the lowest plausible amount for a non-dieting, weight-stable individual during the survey period. Thus, Goldberg's method defines LERs in our sample as 'those individuals reporting a mean energy intake over the previous 12 months below their specified cut-off limit'.

We compared LERs and non-LERs on a number of sociodemographic, anthropometric, lifestyle and nutritional characteristics previously identified as possibly being associated with underreporting; these included gender, age, weight, BMI, education, perceived financial situation, smoking, exercise levels, supplement use, and percentage of energy from macronutrients.

\section{Statistical analysis}

Statistical analyses were carried out using SPSS software, version 10.0 (SPSS Inc., Chicago, IL, USA, 1999). For continuous variables, differences between two means were assessed by independent-samples $t$-tests, while differences between multiple means were examined using analysis of variance. Differences among groups were submitted to a Bonferroni test to determine which two groups differed. A Mann-Whitney $U$-test was used when a normal distribution was not present for continuous variables. For categorical variables, chi-square tests were performed to identify differences between proportions, at a significance level of $P<0.05$.

\section{Results}

General, physical and selected nutritional characteristics of the participants $(n=246)$ are shown in Table 1 . 
Table 1 General characteristics, BMR and El/BMR of the study population $(n=246)$

\begin{tabular}{|c|c|c|}
\hline Characteristic & $\begin{array}{c}\text { Men } \\
(n=106)\end{array}$ & $\begin{array}{l}\text { Women } \\
(n=140)\end{array}$ \\
\hline Age (years), mean (range) & $46(20-79)$ & $44(18-82)$ \\
\hline $\mathrm{BMR}^{\star}\left(\mathrm{kcal} \mathrm{day}^{-1}\right)$, mean $\pm \mathrm{SD}$ & $1800 \pm 220$ & $1351 \pm 131$ \\
\hline Weight $(\mathrm{kg})$, mean $\pm \mathrm{SD}$ & $83 \pm 15$ & $62 \pm 13.1$ \\
\hline Height $(\mathrm{cm})$, mean \pm SD & $176 \pm 7$ & $162 \pm 8$ \\
\hline \multicolumn{3}{|l|}{ Subjects (\%) with El/BMR } \\
\hline$<1.55$ & 78 & 74 \\
\hline $1.55-2.4$ & 19 & 23 \\
\hline$>2.4$ & 2 & 3 \\
\hline \multicolumn{3}{|l|}{ Subjects (\%) with BMI } \\
\hline$<25.0 \mathrm{~kg} \mathrm{~m}^{-2}$ & 36 & 65 \\
\hline $25.0-30.0 \mathrm{~kg} \mathrm{~m}^{-2}$ & 42 & 24 \\
\hline$>30.0 \mathrm{~kg} \mathrm{~m}^{-2}$ & 22 & 11 \\
\hline \multicolumn{3}{|l|}{ Educational level } \\
\hline Secondary school or less (\%) & 26 & 32 \\
\hline College and higher (\%) & 74 & 68 \\
\hline \multicolumn{3}{|l|}{ Perceived financial situation } \\
\hline Adequate (\%) & 87 & 85 \\
\hline Poor (\%) & 13 & 15 \\
\hline \multicolumn{3}{|l|}{ Physical activity } \\
\hline Light (\%) & 49 & 74 \\
\hline Moderate and higher (\%) & 51 & 26 \\
\hline
\end{tabular}

BMR - basal metabolic rate; El/BMR - ratio of energy intake to BMR; SD - standard deviation; BMI - body mass index.

*BMR estimated with Schofield's equations (1985).

\section{Energy intake and $\mathrm{EI} / \mathrm{BMR}$ related to sex and age}

The average EI/BMR ratio of the survey participants was 1.26 (SD 0.55) for men and 1.32 (0.4) for women, indicating that $43 \%$ of respondents overall were LERs.
A considerable proportion of men (78\%) and women (74\%) had an EI/BMR ratio of 1.55 or lower (Fig. 1). Our results also indicate that $54 \%$ of participants had a reported intake below $1.27 \times \mathrm{BMR}$, which is considered by the $\mathrm{FAO} / \mathrm{WHO} / \mathrm{UNU}$ to be the minimal energy intake for survival. Average reported energy intakes for men were 2271 (SD 1006) kcal and 1776 (572) kcal for women. We classified 57 men (54\%) and 59 women (35\%) falling below their cut-off limit as LERs when participants were grouped into three physical activity levels. As the difference in proportions of LERs between the genders was highly significant $(P=0.003)$, we performed all subsequent analyses separately by gender. We also verified whether a single EE/BMR ratio of 1.55 (sedentary) for the whole group would affect the number of male and female LERs. The analysis performed demonstrated no significant difference in proportions of LERs by gender (data not shown). This result was anticipated, as an EE/BMR ratio of 1.55 can only identify gross underreporting of energy intake. Men were more active than women in our study, so they were not detected as LERs when a sedentary physical activity level was considered.

\section{Selected characteristics of LERs and non-LERs}

We found a number of significant differences in characteristics between LERs and non-LERs in both men and women (Table 2). Male LERs were more likely to have a higher BMI $(P=0.046)$, to consider their financial situation as adequate $(P=0.01)$ or to consume a higher

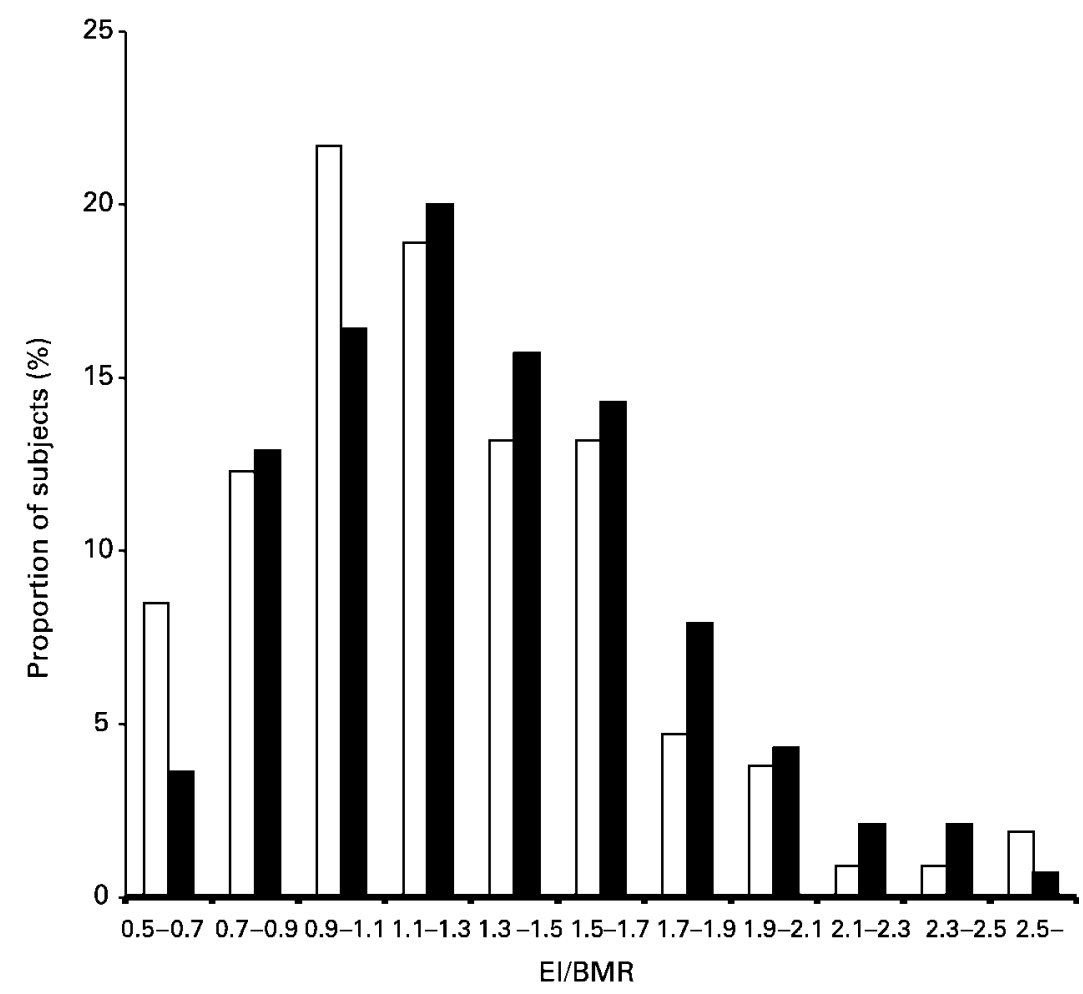

Fig. 1 Distribution of the ratio of energy intake to basal metabolic rate (El/BMR) among men ( $n=106)$ (white bars) and women $(n=140)$ (black bars) derived from self-reported physical activity and food-frequency questionnaire data 
Table 2 Sociodemographic, health, lifestyle, socio-economic and nutritional characteristics of men and women LERs and non-LERs

\begin{tabular}{|c|c|c|c|c|}
\hline \multirow[b]{2}{*}{ Characteristic } & \multicolumn{2}{|c|}{ Men } & \multicolumn{2}{|c|}{ Women } \\
\hline & $\operatorname{LER}(n=57)$ & Non-LER $(n=49)$ & $\operatorname{LER}(n=49)$ & Non-LER $(n=91)$ \\
\hline Weight $(\mathrm{kg})$, mean $\pm \mathrm{SD}$ & $83.8 \pm 16$ & $81.3 \pm 14$ & $66.4 \pm 16$ & $61 \pm 11^{*}$ \\
\hline \multicolumn{5}{|l|}{ BMI distribution (\%) } \\
\hline$<25.0 \mathrm{~kg} \mathrm{~m}^{-2}$ & 26 & $47^{\star}$ & 55 & 70 \\
\hline $25.0-30.0 \mathrm{~kg} \mathrm{~m}^{-2}$ & 53 & 31 & 22 & 25 \\
\hline$>30.0 \mathrm{~kg} \mathrm{~m}^{-2}$ & 21 & 22 & 23 & $5^{\star \star}$ \\
\hline \multicolumn{5}{|l|}{ Age group distribution (\%) } \\
\hline $18-34$ years & 23 & 31 & 16 & 35 \\
\hline $35-49$ years & 32 & 39 & 31 & 37 \\
\hline $50-64$ years & 24 & 22 & 39 & 19 \\
\hline $65+$ years & 21 & 8 & 14 & $9^{*}$ \\
\hline \multicolumn{5}{|l|}{ Educational level } \\
\hline Secondary school or less (\%) & 28 & 25 & 45 & 25 \\
\hline College and higher (\%) & 72 & 75 & 55 & $75^{\star}$ \\
\hline \multicolumn{5}{|l|}{ Perceived financial situation } \\
\hline Adequate (\%) & 95 & 78 & 78 & 89 \\
\hline Poor (\%) & 5 & $22^{*}$ & 22 & 11 \\
\hline \multicolumn{5}{|l|}{ Physical activity } \\
\hline Light (\%) & 50 & 48 & 80 & 70 \\
\hline Moderate and higher (\%) & 50 & 52 & 20 & 30 \\
\hline \multicolumn{5}{|l|}{ Smoking habits } \\
\hline Smoker (\%) & 19 & 37 & 18 & 21 \\
\hline Former smoker (\%) & 42 & 29 & 25 & 28 \\
\hline Non-smoker (\%) & 39 & 34 & 57 & 51 \\
\hline Energy $\left(\mathrm{kcal}_{\text {day }}{ }^{-1}\right)$, mean $\pm \mathrm{SD}$ & $1686 \pm 483$ & $2952 \pm 1030^{\star \star \star}$ & $1240 \pm 223$ & $2065 \pm 487^{\star \star \star}$ \\
\hline $\operatorname{BMR}\left(\mathrm{kcal} \mathrm{day}^{-1}\right)$, mean $\pm \mathrm{SD}$ & $1806 \pm 246$ & $1794 \pm 188$ & $1379 \pm 156$ & $1337 \pm 114$ \\
\hline El/BMR & 0.93 & $1.64^{\star \star *}$ & 0.90 & $1.55^{\star \star \star}$ \\
\hline Total fat (\% energy) & 31.6 & 33.1 & 31.7 & $35.5^{\star \star}$ \\
\hline Carbohydrate (\% energy) & 47.5 & 46.4 & 49.6 & $45.6^{\star}$ \\
\hline Protein (\% energy) & 17.5 & $15.7^{\star}$ & 16.4 & 17.0 \\
\hline
\end{tabular}

LER - low energy reporter; SD - standard deviation; BMI - body mass index; BMR - basal metabolic rate; El/BMR - ratio of energy intake to BMR.

Differences between means were tested by the Student $t$-test, and differences between proportions were tested by the chi-square test: * $P<0.05 ;{ }^{* \star}, P<0.01 ;{ }^{* \star}, P<0.001$.

percentage of energy as protein $(P=0.005)$ compared with non-LER participants. Female LERs were found to be older $(P=0.01)$, heavier $(P=0.04)$, have higher BMI $(P=0.02)$ and be more likely to report foods containing a higher percentage of carbohydrate $(P=0.02)$ or a lower percentage of fat $(P=0.002)$ than their non-LER counterparts. They also had lower education levels than non-LER women.

\section{Discussion}

The present study sought to evaluate the prevalence of underreporting of energy intake from the FFQ and to determine whether LERs and non-LERs differed on certain characteristics. In 1991, Black et al. showed that underreporting of energy intake is widespread and can seriously affect dietary interpretation ${ }^{5}$. After assessing underreporting from the FFQ, we concluded that $43 \%$ of individuals were LERs when evaluated by Goldberg's technique. That is, it was statistically improbable that their reported energy intake would represent their habitual intake over the previous year.

The strength of this study lies in the self-assessed physical activity questions in the FFQ which allowed us to apply light, moderate or heavy EE/BMR ratios to determine the cut-off limits, rather than using a standard sedentary physical activity level of $1.55 \times$ BMR for the entire sample. The FAO/WHO/UNU defines $1.55 \times$ BMR as the expected energy requirement for light activity (sedentary lifestyle). This technique has a sensitivity of 0.74 and 0.64 , and specificity of 0.97 and 0.98 (men and women, respectively) ${ }^{22}$. On the other hand, because it has been shown that underreporting is present at all levels of energy expenditure, a sedentary level of 1.55 attributed to all subjects can only identify about $50 \%$ of underreporters. Consequently, Black has recommended that all dietary surveys should include some measurement of physical activity, weight and height, in order to evaluate reported energy intake at the individual level ${ }^{23}$. This recommendation results from studies of doubly labelled water showing that extreme variation in energy expenditure is present at all ages ${ }^{3}$.

The doubly labelled water technique cannot be used with a large number of participants in an epidemiological study, which explains the widespread use of the Goldberg statistical cut-off for EI/BMR. Use of the Goldberg technique is still subject to some criticism because of its lack of precision. In addition, in the present analyses, BMR 
was estimated by Schofield's formula based on selfreported height and weight ${ }^{20}$. Consequently, BMR might be biased (overestimated) among individuals who incorrectly reported their height and weight, in obese individuals who have a higher percentage of body fat, or among persons over 60 years of age. The lower confidence limit (cut-off) is only a value below which is it statistically unlikely that a reported energy intake is plausible . $^{22}$.

Our results are similar to those of other studies that have estimated underreporting of energy intake from an FFQ using Goldberg's technique. The EPIC (European Prospective Investigation into Cancer and Nutrition) Potsdam survey evaluated energy intake data from a semiquantitative FFQ by the cut-off limit of 1.35 , and suggested underreporting among approximately $40 \%$ of subjects ${ }^{24}$. The study of Samaras et al. was very similar to ours in terms of the number of subjects, the period of dietary assessment of the Oxford FFQ (1 year) and the use of three levels of EE/BMR (light, moderate, heavy) for the cut-off limit ${ }^{6}$. They concluded that $52 \%$ of participants were underreporters. In an Irish study (Kilkenny Health Project), reported energy intake from an FFQ below a cut-off of 1.27 identified $53 \%$ of subjects as underreporters $^{25}$. Another FFQ administered in the UK evaluated close to $39 \%$ of men and $28 \%$ of women as underreporters $^{26}$. It must be noted that dietary underreporting is not confined to FFQs, but occurs with all dietary assessment methods, indicating a possibly consistent aberrant behaviour when nutritional evaluation is performed $^{3,7}$.

It is likely that the underreporting detected in our study is a complex phenomenon. We can only speculate as to the actual mechanisms operating here, because this bias is present in a number of subgroups and across the complete range of energy expenditure as defined in this study. Lack of motivation and the inability or unwillingness on the part of the subjects to correctly report intake is a possible explanation, with consequences for the accuracy of the FFQ. Underreporters might have deliberately or unconsciously erred when estimating frequencies and/or portion sizes. It is generally recognised that eating unhealthy foods is not perceived as a good behaviour, so that snack foods high in sugar and fat and regarded as 'junk foods' could very well be underreported. Weight-conscious individuals, those who frequently diet to lose weight and people concerned with their body image are well known to underreport their food intake $\mathrm{e}^{9,11}$. In the elderly, memory problems may have affected reporting accuracy, especially as participants were called upon to provide diet information for the previous 12 months. The structure of the FFQ itself (food items, frequency categories and reference portion sizes) could be a source of error. The reference portion size photos included in the FFQ may have been misused by participants or not used at all, which would affect the accuracy of the portion size choices (smaller than, equal to or larger than the reference). However, it must be stressed that the FFQ was found to have a respectable level of overall validity, and only minimal misclassification as assessed in relation to four non-consecutive food records, with results very similar to those reported in the dietary assessment literature ${ }^{18,19}$.

LERs and non-LERs had similar BMR and self-reported physical activity levels. While participants may have incorrectly reported their physical activity, BMR is unlikely to explain the lower energy intakes reported by the LERs. BMR calculations were used in the Schofield equations, which assume a linear relationship between body weight and BMR. However, as fat tissue is less active metabolically than lean mass, obese individuals could have been misclassified as LERs. Contrary to most studies of low energy reporting ${ }^{27-30}$, men in our sample were more likely than women to emerge as LERs (54\% of men, compared with $35 \%$ of women). To our knowledge, there are only three studies that have identified a higher percentage of male LERs ${ }^{26,31,32}$. It is unclear whether men underreport to a lesser degree than women, or if they underreport to the same degree as women but from a higher energy requirement, and would thus be less likely to fall below a single cut-off limit applied to all subjects ${ }^{22}$. This observation could very well explain our higher percentage of male LERs, because our study included an evaluation of physical activity to identify LERs across all levels of energy expenditure as defined in this study. Very few studies of low energy reporting have provided this type of evaluation of physical activity so they may have been unable to detect certain underreporters, such as men with high energy expenditure. On the other hand, since women are typically more conscious of and familiar with their serving sizes than men, their self-reports of energy intake may be more precise. Some respondents reported having problems estimating the number of hours they spent at different levels of physical activity, and may have reported what they perceived as desirable rather than a true reflection of their usual practices. Since many people are sedentary, this could have produced an overestimate of their physical activity levels, which would have affected our calculation of energy expenditure. As with other selfreported behaviours, respondents may have difficulty assessing and reporting their physical activity level from summary questions providing different levels of energy expenditure, such as those used in the questionnaire.

Obesity defined by BMI was prevalent in a higher proportion of LERs than non-LERs, in agreement with other studies ${ }^{33-36}$. BMI seems to be one of the most consistent factors in predicting underreporting of energy intake in nutritional assessment studies ${ }^{7}$. Attitudes about their body weight and the desire to reduce weight influence how obese individuals report their dietary intakes $^{11}$. Some studies have shown that dieters and individuals with high dietary restraint associated a higher 
level of guilt to eating sweets, salty snacks, high-calorie and high-fat foods, and were less likely to report eating these foods $2,37,38$. Again, as described above, the Schofield equations might have overestimated the BMR of obese individuals as they have less lean mass and, as a result, produced a misclassification of LERs.

A number of other observations on the characteristics of adequate reporters and underreporters in our sample may provide directions for further investigation. While these did not reach statistical significance, trends were detected suggesting differences between LERs and non-LERs (which also varied by gender) in other macronutrient intakes, smoking and physical activity habits (Table 2). These observations highlight areas for further vigilance in dietary assessment and interpretation of self-reports.

In conclusion, the average EI/BMR ratios of survey participants indicated that $43 \%$ of them were LERs. However, low energy reporting was unevenly distributed in this sample of Montreal adults, with male and female LERs having higher BMI levels, and female LERs being older and less educated, than their respective non-LER counterparts. These distinguishing attributes have been reported in other studies. Differences in macronutrient intakes between men and women LERs and non-LERs may also suggest differential dietary self-reports characteristic of dieters, or those observed among individuals with dietary restraint. Questions also remain on the applicability of estimates of basal metabolism in certain population subgroups, as well as the ability of respondents to assess their physical activity expenditure. Still, awareness of underreporting is of key importance if we are to improve dietary assessment methodology. Findings from this study can help investigators to assess and interpret dietary self-reports and develop strategies for minimising error in susceptible participant groups.

\section{Acknowledgements}

This research was supported by a grant from the joint Fonds de la Recherche en Santé du Québec-Santé Québec (FRSQ-SQ) programme for the analysis of survey data, project number 001027 , and a graduate bursary to the first author from the Départment de Nutrition, Université de Montréal.

\section{References}

1 Cook A, Pryer J, Shetty P. The problem of accuracy in dietary surveys. Analysis of the over $65 \mathrm{UK}$ national diet and nutrition survey. Journal of Epidemiology Community Health 2000; 54: 611-6.

2 Lafay L, Mennen L, Basdevant A, Charles MA, Borys JM, Eschwege E, et al. Does energy intake underreporting involve all kinds of food or only specific food items? Results from the Fleurbaix Laventie Ville Santé (FLVS) study. International Journal of Obesity and Related Metabolic Disorders 2000; 24: 1500-6.

3 Hill RJ, Davies PSW. The validity of self-reported energy intake as determined using the doubly labelled water technique. British Journal of Nutrition 2001; 85: 415-30.

4 Goldberg GR, Black AE, Jebb SA, Cole TJ, Murgatroyd PR, Coward WA, et al. Critical evaluation of energy intake data using fundamental principles of energy physiology: 1 Derivation of cut-off limits to identify under-recording. European Journal of Clinical Nutrition 1991; 45: 569-81.

5 Black AE, Goldberg GR, Jebb SA, Livingstone MBE, Cole TJ, Prentice AM. Critical evaluation of energy intake data using fundamental principles of energy physiology: 2. Evaluating the results of published surveys. European Journal of Clinical Nutrition 1991; 45: 583-99.

6 Samaras K, Kelly PJ, Campbell LV. Dietary underreporting is prevalent in middle-aged British women and is not related to adiposity (percentage body fat). International Journal of Obesity and Related Metabolic Disorders 1999; 23: 881-8.

7 Johansson G, Wikman A, Ahrén A-M, Hallmans G, Johansson I. Undereporting of energy intake in repeated 24-hour recalls related to gender, age weight status, day of interview, educational level, reported food intake, smoking habits and area of living. Public Health Nutrition 2001; 4: 919-27.

8 Krebs-Smith SM, Graubard BI, Kahle LL, Cleveland LE, Ballard-Barbash R. Low energy reporters vs others: a comparison of reported food intakes. European Journal of Clinical Nutrition 2000; 54: 281-7.

9 Taren DL, Tobar M, Hill A, Howell HW, Shisslak C, Bell I, et al. The association of energy intake bias with psychological scores of women. European Journal of Clinical Nutrition 1999; 53: 570-8.

10 Livingstone MBE, Black AE. Markers of the validity of reported energy intake. Journal of Nutrition 2003; 133: 895S-920S.

11 Johansson L, Solvoll K, Bjornehoe G-EA, Drevon CA. Underand overreporting of energy intake related to weight status and lifestyle in a nationwide sample. American Journal of Clinical Nutrition 1998; 68: 266-74.

12 Hivonen T, Männistö S, Roos E, Pietinen P. Increasing prevalence of underreporting does not necessarily distort dietary surveys. European Journal of Clinical Nutrition 1997; 51: 297-301.

13 Briefel RR, Sempos CT, McDowell MA, Chien S, Alaimo K. Dietary methods research in the third National Health and Nutrition Examination Survey: underreporting of energy intake. American Journal of Clinical Nutrition 1997; 65(Suppl. 4): 1203S-9S.

14 Goris AHC, Meijer EP, Kester A, Westerterp KR. Use of a triaxial accelerometer to validate reported food intakes. American Journal of Clinical Nutrition 2001; 73: 549-53.

15 Shatenstein B, Nadon S, Godin C, Ferland G. Challenges in developing an instrument to assess overall dietary and nutritional quality. Canadian Journal of Dietetic Practice and Research 2002; 63(2): 113 [abstract].

16 Waksberg J. Sampling methods for random digit dialing. Journal of the American Statistical Association 1978; 73 40-6.

17 Block G, Hartman AM, Dresser CM, Carroll MD, Gannon J, Gardner L. A data-based approach to diet questionnaire design and testing. American Journal of Epidemiology 1986; 124: 453-69.

18 Shatenstein B, Nadon S, Godin C, Ferland G. Validation of a population-based food frequency questionnaire using four food records. Conference Proceedings. International Journal of Epidemiology Supplement, August 2002, abstract WP 120 .

19 Shatenstein B, Nadon S, Godin C, Ferland G. Development and validation of a food frequency questionnaire in Montreal. Canadian Journal of Dietetic Practice and Research 2004; in press.

20 Schofield WN, Schofield C, James WPT. Basal metabolic rate. 
Human Nutrition: Clinical Nutrition 1985; 39C (Suppl. 1): $1-96$.

21 Food and Agriculture Organization (FAO)/World Health Organization (WHO)/United Nations University (UNU). Energy and Protein Requirements. Report of a Joint FAO/WHO/UNU Consultation. Technical Report Series No. 724. Geneva: WHO, 1985.

22 Black AE. The sensitivity and specificity of the Goldberg cutoff for EI:BMR for identifying diet reports of poor validity. European Journal of Clinical Nutrition 2000; 54: 395-404.

23 Black AE. Physical activity level from a meta-analysis of doubly labeled water studies for validating energy intake as measured by dietary assessment. Nutrition Reviews 1996; 54: $170-4$.

24 Voss S, Kroke A, Klipstein-Grobusch K, Boeing H. Is macronutrient composition of dietary intake data affected by underreporting? Results from the EPIC-Postdam study. European Journal of Clinical Nutrition 1998; 52: 119-26.

25 Becker W, Foley S, Shelley E, Gibney M. Energy underreporting in Swedish and Irish dietary surveys: implications for food-based dietary guidelines. British Journal of Nutrition 1999; 81(Suppl. 2): S127-31.

26 Mennen LI, Jackson M, Cade J, Mbanya JC, Lafay L, Sharma S, et al. Underreporting of energy intake in four populations of African origin. International Journal of Obesity and Related Metabolic Disorders 2000; 24: 882-7.

27 Price GM, Paul AA, Cole TJ, Wadsworth EJ. Characteristics of the low-energy reporters in a longitudinal national dietary survey. British Journal of Nutrition 1997; 77: 833-51.

28 Pryer JA, Wrijheid M, Nichols R, Kiggins M, Elliot P. Who are the 'low-energy reporters' in the Dietary and Nutritional Survey of British Adults? International Journal of Epidemiology 1997; 26: 146-54.

29 Heywood P, Harvey PWJ, Marks GC. An evaluation of energy intakes in the 1983 Australian National Dietary Survey of Adults. European Journal of Clinical Nutrition 1993; 47: 604-6.

30 Fogelhom M, Männistö S, Vartiainen E, Pietinen P.
Determinants of energy balance and overweight in Finland 1982 and 1992. International Journal of Obesity and Related Metabolic Disorders 1996; 20: 1097-104.

31 Lafay L, Basdevant A, Charles MA, Vray M, Balkau B, Borys $\mathrm{JM}$, et al. Determinants and nature of dietary underreporting in a free-living population: the Fleurbaix Laventie Ville Santé (FLVS) study. International Journal of Obesity and Related Metabolic Disorders 1997; 21: 567-73.

32 Gnardellis C, Boulou C, Trichopoulou A. Magnitude, determinants and impact of under-recording of energy intake in a cohort study in Greece. Public Health Nutrition 1998; 1: 131-7.

33 Harrison GG, Galal OM, Ibrahim N, Khorshid A, Stormer A, Leslie J, et al. Underreporting of food intake by dietary recall is not universal: a comparison of data from Egyptian and American women. Journal of Nutrition 2000; 130: 2049-54.

34 Rothenberg E, Bosaeus I, Steen B. Evaluation of energy intake estimated by a diet history in three free-living 70 year old populations in Gothenberg, Sweden. European Journal of Clinical Nutrition 1997; 51: 60-6.

35 Jonnalagadda SS, Mitchell DC, Smiciklas-Wright H, Meaker $\mathrm{KB}$, Van Heel N, Karmally W, et al. Accuracy of energy intake data estimated by a multiple-pass, 24 hour dietary recall technique. Journal of the American Dietetic Association 2000; 100: 303-8.

36 Klesges RC, Eck LH, Ray JW. Who underreports dietary intake in a dietary recall? Evidence from the Second National Health and Nutrition Examination Survey. Journal of Consulting and Clinical Psychology 1995; 63: 438-44.

37 Sunday SR, Einhorn A, Halmi KA. Relationship of perceived macronutrient and caloric content to affective cognitions about food in eating-disordered, restrained, and unrestrained subjects. American Journal of Clinical Nutrition 1992; 55: 362-71.

38 Kirkley BG, Burge JC, Ammerman A. Dietary restraint, binge eating, and dietary behavior patterns. International Journal of Eating Disorders 1988; 7: 771-8.

\section{Appendix}

The following questions were developed from Kino-Québec, a Quebec government programme devoted to the promotion of physical activity in the population (http://www.kino-quebec.qc.ca/recherch/fs_rec.htm) in order to classify individuals into light, moderate or heavy physical activity level (PAL) as described by the World Health Organization.

How many hours per week do you usually spend doing the following activities? Number of hours per week (write 0 if none)

A) Low-intensity activities (work done standing up, e.g. by electricians, cooks, nurses and cashiers; gardening, light cleaning, babysitting children, bowling, social dancing, walking at a normal pace, tai chi, etc.)

B) Medium-intensity exercises (moderate manual work, e.g. done by a carpenter; loading and unloading, mowing the lawn, raking leaves, shovelling snow, walking at a fast pace, biking $\left(15 \mathrm{~km} \mathrm{~h}^{-1}\right)$, cross-country skiing on a flat surface, golf, swimming with medium effort, etc.)

C) High-intensity exercises (aerobics and fitness training, badminton, biking $\left(20 \mathrm{~km} \mathrm{~h}^{-1}\right)$, jogging, tennis, hockey, vigorous swimming, hiking with backpack, etc.)

D) Very-high-intensity exercises (transporting heavy loads, forestry work, running, soccer, racquetball or squash, martial arts, etc.) 